\title{
Uma idéia de verdade idéias, formas e condições da crítica \\ Emanuele Zinato
}

1.

A crítica literária é ou deveria ser exercício de verdade. Tal afirmação, entretanto, só pode soar grotesca em uma época na qual a mentira se instalou no centro do poder. Quem se propõe, em qualquer âmbito disciplinar, a perseguir uma idéia pessoal de verdade se sente imediatamente atingido por uma rajada derrisória de reprovação: será lembrado que todo discurso é ficção, retórica e narração, ${ }^{1}$ que os fatos não resistem, ${ }^{2}$ que relativismo e incerteza governam o mundo. O crítico, até há poucas décadas, era um intelectual: fazia parte daquele grupo apartado de figuras públicas descendentes distantes dos philosophes que defendiam como direito e dever coletivo agir sobre o intelecto, praticar a unidade de verdade, valores morais e senso estético. Atualmente, contudo, ele se encontra privado de

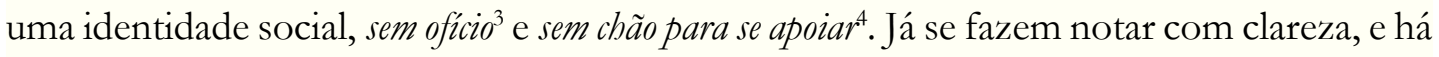
algum tempo, também no restrito âmbito da crítica italiana, sintomas convulsivos e obsessivos em conseqüência da perda da função do intelectual legislador ${ }^{5}$ o recuo diante do território profissional, que é considerado ainda relativamente a salvo; a construção fantasmática desvinculada do exame da realidade de um agente histórico participante de uma sociedade racionalmente organizada; a recusa de qualquer teoria sobre o mundo e de qualquer confronto com uma comunidade de intérpretes, complementado pelo naufrágio subjetivista.

Poderiam pertencer à categoria do recuo dois livros de Cesare Segre, Notizie dalla crisi $^{6}$ e Ritorno alla critica, ${ }^{7}$ que abriram e fecharam o longo debate sobre a crise da crítica e da italianística ${ }^{8}$. Em Ritorno alla critica, em particular, proclama-se a perene majestade do texto que permanece ali com seus tesouros de beleza , ' que representa todo o nosso bem , e que na sua majestade coincide com a verdade ${ }^{10}$. Essa volta ao texto-verdade constitui o primeiro mandamento do juramento de Hipócrates ${ }^{11}$ que Segre propõe aos críticos literários, diante da invasão do desconstrucionismo reader-oriented. Não é casual, portanto, que no livro se distinga claramente entre uma hermenêutica relativa à atividade filológica e uma nova hermenêutica inevitavelmente dirigida, em todas as suas manifestações recentes, a uma tomada de posição . Tal textualismo, entretanto, ao evitar o naufrágio das interpretações, corre o risco de tornar a crítica estável, mas sem vitalidade cognitiva. É extremamente difícil, na verdade, manter o espírito crítico sem, ao mesmo tempo, avaliar a nossa situação e a do mundo .

A perene majestade do texto Edoardo Sanguinetti parece substituir pela imortal presença do intelectual e da classe: 
Para mim (...) uma coisa permanece certa: é a idéia gramsciana de que, assim como, num certo sentido, essencial e radical, todos os homens são intelectuais, do mesmo modo que, naturalmente, (...) todos os intelectuais, em todos os sentidos, são orgânicos sempre. (...) A consciência de classe, não somente nos intelectuais evidentemente, mas também em todos os homens dos diversos lugares do mundo, (..) pode muito bem eclipsar-se, por tempos longos e mesmo longuíssimos, chegando até mesmo à extinção. Pouco importa; a luta de classe, querendo-se ou não, essa continua. ${ }^{12}$

Trata-se do clero orgânico, postula gramscianamente um intelectual orgânico na época do intelectual-mediático. Sanguineti, mesmo que a partir do fim das mediações culturais, continua pensando que os grupos sociais hegemônicos elaboram ainda a imagem de um corpo separado dos clérigos tradicionais com a presunção de autonomia e de independência. ${ }^{13}$ E espera com otimismo voluntarista a revolução proletária praticável em plena era da globalização imperialista. ${ }^{14}$ Tal imperativo categórico é visto à luz do presente e, concomitantemente, com um misto de obstinação ideológica e de melancolia histórica crepuscular, ${ }^{15}$

Eu sei, era o tempo no qual se pensava a missão do novo douto como milícia coletiva para um internacionalismo proletário. Acaba de acontecer, mas parece que já faz uma eternidade. Hoje estamos assistindo à agonia planetária dessa hipótese de trabalho. ${ }^{16}$

A hipostasia de uma verdade subjetiva não verificável e o conseqüente fastídio pela teoria, resumindo, o retorno da crítica de gosto, parecem entretanto ser, há uma década, a dominante da prosa dos críticos mais jovens. ${ }^{17}$ Trata-se daqueles que Segre chamou de críticos-pavões , para os quais a obra, qualquer que seja, pode e deve ser rebaixada em nome da invenção que ostenta as cores da própria fantasia.$^{18} \mathrm{O}$ ícone juvenil do crítico literário $^{19}$ é na verdade o do crítico-artista, no qual o eu lírico e o eu crítico se fundem sem nenhum escrúpulo, gerando insondáveis curto-circuitos analógicos. Manifesto da jovem crítica é a Introduzione in Forma di Dialogo ${ }^{20}$ que Silvio Perrella publicou na abertura da edição de Critico come Artista, de Oscar Wilde. Perrella afirma, citando Wilde, que a crítica é a forma mais pura de impressão pessoal, e é mais criativa que a criação , acrescentando que com uma afirmação desse tipo são jogadas ao mar muitas petições de princípios que dizem respeito à objetividade científica que é necessária a essa atividade.

Como é notório, não existe ideologia mais coercitiva e parcial daquela que se autoabsolve do pecado ideológico .

Também Costellazioni Italiane 1945-1999, ${ }^{21}$ uma espécie de repertório crítico e fotográfico, com o qual três jovens críticos relêem a segunda metade do século XX, elencando os cinqüenta livros capazes de nos restituirem uma contra-História da Itália , ${ }^{22}$ é sintomático para compreender as orientações e as tendências dessa zona geracional da crítica italiana. A grande taxa de diarismo e de literariedade dessa prosa, e até mesmo seu ritmo mimético, esconde uma, ainda que subentendida, pulsão para o ensaísmo, como reação, especular, a tanta objetividade. Não é casual que esses críticos considerem Giacomo Debenedetti como o mestre absoluto, nem que interpretem a lição sobretudo como fim dos esquemas teóricos e dos freios à subjetividade. A noção que Perrella parece extrair de 
Debenedetti, de crítico-homem , prescreve uma aproximação aos textos sem nenhuma rede de proteção.$^{23}$

O subjetivismo traz inevitavelmente consigo uma estrondosa presunção e a exibição do direito à incoerência. Um dos críticos mais agressivos dos últimos anos, Carla Benedetti, demonstra preferir a nä̈veté e o protagonismo, praticados ao mesmo momento em que os denuncia. ${ }^{24}$ Com um título de efeito, ${ }^{25}$ modelado sobre o de Julien Benda (Il Tradimento dei Critici), Benedetti parece querer atingir o centro nevrálgico do conjunto mentiroso dos profissionais da crítica, contrapondo-se à verdade veiculada por um grupo restrito de escritores, entre os quais se destaca Antonio Moresco. Por detrás do vigor e do conteúdo escandaloso da exibição, está a necessidade, corajosa embora totalmente reificada, de romper com a auto-referencialidade da crítica literária, pondo-a diante da atual guerra permanente. ${ }^{26}$ Mas, diante da cegueira automática do domínio neoliberal, capaz de promover guerra, mercadorias culturais e consenso por conta prórpia, sem precisar dos intelectuais, o crítico inverte sua objetiva impotência em subjetiva onipotência: ao invés de produzir uma reflexão sobre a condição atual do trabalho intelectual, Benedetti retira de si mesma, como o prestigitador, o coelho da cartola, a formulação do crítico como parresiastés, aquele que diz a verdade num contexto de risco.${ }^{27}$

A mistura de ensaísmo e pensamento crítico, o balizamento entre subjetividade e objetividade, o curto-circuito entre interno e externo, mal-entendidos pelos jovens críticos do novo século, foram verdadeiras e sofridas estratégias de escritura de dois dos mais notáveis ensaístas do século passado. Superexposto e mal compreendido, o primeiro; reduzido a uma caricatura ideológica, o outro: Giacomo Debenedetti e Franco Fortini.

Debenedetti é mestre da crítica osmótica e analógica, de desenfreada e furiosa vocação interdisciplinar. Nas suas páginas domina o curto-circuito: entre ciência e literatura, e entre diversos fatos artísticos, em primeiro lugar, entre o musical e o literário. Contrariamente aos críticos especialistas, Debenedetti jamais ostenta frieza objetiva , pelo contrário, mostra-se sempre compromissado com o texto, na tentativa de desencavar o que há de subjetivo no objetivo, levando ao ponto de fusão entre externo e interno, objeto e sujeito. Enquanto aos modernos admiradores de Debenedetti falta totalmente o demônio da dialética, Debenedetti, por sua vez, frisa a necessidade de exorcizar a margem autobiográfica da crítica porque se está perigosamente próximo dela: O crítico tem a obrigação moral de calar as insinuações perturbadoras a respeito da própria biografia: dos seus mitos familiares deve excluir, com agudo zelo, o de Narciso.$^{28}$

O crítico ensaísta aceita o desafio - no fundo, ético - de basear a interpretação sobre o conteúdo de fato de uma obra, mas sabe que os significados que elabora dependem em larga medida da própria situação biográfica e da condição histórica em que vive: tratase de uma bipolaridade conectada ao próprio fazer crítico. A escritura de Debenedetti evita, assim, também os riscos da vertente oposta, do excesso cientificista, realizando uma solidariedade singular entre imagens e pensamentos, entre metáforas e idéias. ${ }^{29}$ É exemplar, 
nesse sentido, o colóquio com Montaigne. ${ }^{30}$ Para Debenedetti, ao se ler os ensaios de Montaigne,

ficamos nos perguntando se não são as métaforas que levam o discurso para adiante, que fazem surgir as idéias, que dão o impulso para o discurso, muito mais do que vir do movimento das idéias o impulso que provoca as metáforas.

O gênero ensaístico, inaugurado por Montaigne, parece desmentir a grande dicotomia segundo a qual na prosa, no discurso racional, as imagens estão apenas em função do conteúdo , enquanto que, na poesia, teriam um valor privilegiado, inevitável, inderrogável. Debenedetti confiou às metáforas uma pessoal teoria da crítica .É o estilo o que lhe permite o controlado e cuidadosíssimo curto-circuito, estilística e conceitualmente vital. Como o menino que, ao mesmo tempo, acredita e desacredita na verdade do lobo das fábulas, o crítico exercita uma forma superior de credulidade: deve saber acreditar no conteúdo de verdade daquele mundo ficcional que ele encontra nos livros em forma de metáfora. ${ }^{31}$ Isso significa não tanto a ausência quanto o uso não prevaricante e aberto da teoria, e o emprego de um sistema mental pessoal, condensado em um estilo.

Com Debenedetti, o ensaio crítico é, portanto, e num certo sentido, um objeto literário: possui sua vertente expressiva, retórica. O crítico prefigurado por Debenedetti

não deve jamais se render ao inefável, deve saber que seu trabalho é justamente o de dar sentido através do verbo àqueles segredos, ao que existe de inefável. (...) Sua honra como crítico já estará bem defendida se, tentadas todas as estradas possíveis, terá ao menos indicado, circunscrito, do melhor modo possível, aquele ponto renitente de mistério. ${ }^{32}$

$\mathrm{Na}$ própria descida ao inferno, ao ajustar as contas com as tensões psíquicas e sociais que povoam os grandes textos literários, o crítico deverá portanto se munir da coragem de Euforion, mas também da humildade de quem sabe que deverá ser Jacó e não o anjo. Sua tarefa é em primeiro lugar racionalizar e circunscrever o inefável. Debenedetti, conjugando psicanálise e iluminismo, procura então transformar o arbítrio individual do crítico e as ambivalências do inconsciente em matéria socialmente transmissível, tende a liberar os arquétipos da anonímia das estruturas atemporais, infestantes, implacáveis , para fazer deles um produto da nossa história , puros e verdadeiros utensílios funcionais, iluminadores .

Os ensaios críticos de Fortini convencido, como Merleau-Ponty, que nenhuma página seja digna de ser escrita se não for contribuir para tornar menos fatal a desordem e menos insensata a morte ${ }^{33}$ são, por outro lado, tomados por mortais tensões internas. Como Debenedetti, Fortini também é ensaísta multidisciplinar, alguém convencido de que o crítico, diferentemente do especialista de literatura, é aquele que fala da obra em relação àquilo que acredita, confrontando a mensagem literária com todas as outras mensagens que chegam até ele. 
Todo texto ensaístico de Fortini, embora se apresente obliquamente como pesquisa improvisada e ingrata, reflexão sobre um detalhe, fragmento de memória, é fulgurado por uma lucidez cognitiva sem igual; é, portanto, uma mônada, uma totalidade, e tende a fornecer em um detalhe uma visão inteira do mundo.

Fortini trabalha com o detalhe, escava em profundidade partindo de particulares mínimos, para, em seguida, de um momento ao outro, passar a uma perspectiva geral jamais representada por inteiro, mas sempre e somente como alusão. Suas pesquisas analíticas podem parecer casuais ou até mesmo profissionais, mas inesperadamente vão além do dado analítico para daí extrair, com sínteses fulgurantes, um julgamento histórico.

Para Fortini freqüentemente lido como crítico exclusivamente ideológico o fenômeno estético está inteiramente dissociado da ideologia autoral. A divisão entre classes, que talha como uma navalha o eu e o inconsciente, esquarteja as obras. O relevo dado às interrupções memorialistas e epifanias, muito presentes em Fortini prescinde da prisão do eu. Fortini tende a descobrir no fato literário a recuperação de instantes epifânicos não submetidos ao sufrágio do arbítrio individual, mas sim a uma dimensão intersubjetiva. Nesse sentido, é exemplar o célebre ensaio sobre Sereni, de 1966 publicado nos Quaderni Piacentini e, posteriormente, como parte de Saggi Italiani. Nele o sintagma-chave interrupções históricas , intimamente oximorístico remete claramente à figura do inconsciente político, constitutivo de muitos curto-circuitos fortinianos. ${ }^{34} \mathrm{~A}$ formalização poética, independentemente da intenção autoral, é prefiguração de uma forma de vida associada. Para além dos burburinhos do eu, na corrente social entre os homens, o crítico vê a tentativa de vencer a morte, reconhecendo no indivíduo e no ser social as miríades desaparecidas e aquelas ainda não nascidas, no colocar-se amorosamente ao lado do próximo e dos menos próximos, alegoria dos distantes.$^{35}$

\footnotetext{
Os Instrumentos Humanos ${ }^{36}$ é um livro que pode também ser lido como uma representação da história italiana - européia, numa certa medida - dos últimos quinze anos. Não somente pelas indicações de cena: advento da República, reconstrução, a nova indústria, a passagem para o bem-estar do consumo, a guerra da Algéria, a Alemanha do milagre. Mas por puras e verdadeiras interrupções históricas, identificações de atmosferas, de momentos particulares que se tornam sobrecarregados de significados. ${ }^{37}(. .$.
}

Em Breve Secondo Novecento ${ }^{38}$ o modo de proceder de Fortini, pela característica condensação dos textos, leva-o aos resultados mais radicais e peremptórios. O livro é estruturado em ordem alfabética e pressupõe uma periodização do século XX: Fortini individualiza três passagens ou rupturas, depois da Primeira Guerra, com o triunfo do novecentismo ${ }^{39}$; depois, em 1956, com o experimentalismo; a partir dos anos 70, quando todo o arco da ideologia e do saber não especializado se tornou literatura , entendida como textualidade lúdica que pressupõe um leitor-espectador navegante pelos prazeres multimidiáticos e publicitários.

Essas notas críticas são dissimuladas por furor figural: todo um sistema de metáforas a serviço do pensamento, capaz de se tornar apólogo e alegoria. É o caso da imagem barroca do esqueleto por debaixo da cera, utilizada para liquidar, no último Calvino e no Eco, os estilos homólogos à ideologia pós-modernistas: 
Diante das nossas novas plebes, nutridas de lixo cultural há décadas, se os acépticos neohumanistas quiserem escapar do destino exornativo, parece não existirem outras alternativas a não ser a colagem de Eco (Il Nome della Rosa) ou a montagem de Calvino (Se una Notte d Inverno un Viaggiatore). E por debaixo da agradável cera encontra-se o esqueleto.

A tensão argumentativa é portanto veiculada por um estilo altamente pensativo $e$ figural, evidente na prosa sobre Pasolini, por exemplo, povoada pelo mesmo sistema metafórico das coletâneas poéticas fortinianas: conflito é um termo chave, e a figura do esquartejado por cavalos furiosos implica uma divisão temporal que irrompe pela página e que ali introduz a violência histórica dos séculos passados; a acústica alegórica do gritar ininterrupto é freqüentemente emblema do balcão do açougue da história e, ao mesmo tempo, dos limites extremos da biologia; surge o módulo dialético dos opostos complementares (Due Novecento) e, no plano metodológico existe ainda, explícito, o elogio da mônada (Anche um Campione Minimo).

Há dois Novecento em conflito na poesia de Pier Paolo Pasolini. Sabemos hoje que, apesar da furiosa vontade crítica do autor, nem um nem outro fundou uma alternativa real para o desenvolvimento da poesia italiana do nosso século. O primeiro Novecento é o de seus versos juvenis em dialeto friulano, preciosa reelaboração voluntarista dos motivos protoromânicos, em estilo floral e a la Verlaine.(...) Mas a partir daí, com o característico gesto violentíssimo, que faz de Pasolini alguém esquartejado por furiosos cavalos, deriva toda sua poesia, a qual, de Cenere di Gramsci em diante, procura ser horizontal, discursiva, drasticamente em prosa, mesmo tendo de reacender a velha fogueira da adjetivação da prosa de arte, que Roberto Longhi lhe ensinara, produzindo efeitos extremos como ...mas quase arcos ou espigas/ no mar, no negro mar granulado/a Sardenha ou a Catalunha/há séculos incendiadas (...). Segue em frente, buscando destruir qualquer resíduo canoro(...). O sonho vertical, desconexo, exasperado pelo preciosismo que Pasolini lança, com raiva, por onde passa (...) foi e ele sabia muito bem disso - o sonho pestilento de uma pequena e média burguesia culta não saciada de sublime e, no outro extremo, os gritos ininterruptos de uma prosa ritmada, na qual tudo vale tudo, como na pintura gestual ou automática. Basta uma pequena amostra para nos indicar, ao mesmo tempo e no mesmo espaço, tanto a consciência literária que herdamos do final da guerra, quanto a horrível destruição pessoal e coletiva que Pasolini viveu nos últimos anos.

Correndo o risco de simplificação e de exclusões brutais, eu diria que - na situação do novo século - as idéias e as formas compartilhadas de crítica, marcadas de modo mais forte pelos estilos de Debenedetti e de Fortini, são as de Alfonso Berardinelli e Romano Luperini.

Em ambos a escritura e a experiência de leitura é híbrida de (cuidadosa) escuta autobiográfica e de reflexões cognitivas. Em Luperini predomina a marca reflexivoargumentativa; em Berardinelli, auto-reflexiva e subjetiva.

Por outro lado, considerando distintas a função Debenedetti e a função Fortini , é possível afirmar que é a segunda que nos dá a posição de Luperini, é ela que orienta seu esquema crítico e o estilo. Ao contrário, Berardinelli configura-se tangencialmente a 
Debenedetti, cuja função é explicitamente reinvindicada e contaminada pela de Pasolini, enquanto Fortini, considerado o mestre nos anos 70 , foi em seguida redimensionado e removido.

Por fim, é preciso historicizar as diversas transmissões de heranças, partindo de uma afirmação peremptória - que assume o significado periodicizante de um black-out políticocultural: o fim do intelectual-mediador na Itália foi cruento, constelado por desastres e imposto pela estratégia do terror com a qual as forças dominantes responderam subliminarmente às questões dos movimentos de 1968-73. O pressuposto de que qualquer idéia de projeto desemboque no túnel do totalitarismo, vinculada à evaporação do pensamento crítico, foi, em suma, inculcada com muita energia no corpo social, a partir de 1969 e do decorrer dos anos $70 .^{40}$

\section{Notas}

1 C. Ginszburg se manifestou contra a redução, alimentada pelo ceticismo pós-moderno, do ensaísmo historiográfico à dimensão narrativa ou retórica. Cf. C. Ginszburg, Rapporti di Forza. Teoria, retorica, prova, Milano, Feltrinelli, 2000.

$2 \mathrm{O}$ território ideológico do desaparecimento dos fatos e das posições científicas foi revisto criticamente, em anos recentes, por Gabriele Loli. Cf. Gabriele Loli, Beffe, Scienziati e Stregoni, Bologna, Il Mulino, 1998.

3 A. Berardinelli, Il Critico Senza Mestiere, Milão, Il Saggiatore, 1983.

4 Cf. R. Luperini, Breviario di Critica, Napoli, Guida, p.44.

5 Cfr. Z. Bauman, La Decadenza deggli Intellettuali. Da legislatori a interpreti, Turim, Bollati Boringhieri,1992, pp. 219-221.

6 C. Segre, Notizie dalla Crisi. Dove va la critica letteraria?, Turim, Einaudi, 1993.

7 C. Segre, Ritorno alla Critica, Turim, Einaudi, 2001.

8 Para a bibliografia sobre a discussão cf. Le Schede 1993-1999 , a c. di M. Marucci e V. Tinacci, in Moderna, n. 1, anno II, 2000, pp. 169-177.

9 Ritorno alla Critica, op. cit., p. 86.

10 Op. cit. p. 99.

11 Op. cit. pp. 98-99.

12 E. Sanguineti. Il Chiero Organico. Scritture e Intellettuali, Milano, Feltrinelli, 2000, p. 21.

13 Op. cit. p. 16.

14 Op. cit. p. 310.

15 Esta posição, como revelou agudamente Guido Guglielmi, traz à lembrança o último Vittorini o qual, prevendo precocemente, nos anos do milagre, a crise do intelectual tradicional, foi totalmente favorável à modernização e sarcástico com os escritores pessimistas, mammistas, arcádicos, pré-modernos . O Vittorini de Due tensioni, enfim, que chamou Verga de schifosissimo (nojento) e que, sugerindo ao humanismo tradicional de se desmobilizar , limpou o terreno para o Gruppo 63. G. Guglielmi, in L Immaginazione, n. 173, dicembre 2000, pp. 30-31.

16 Op. cit. p. 21.

17 Emanuele Trevi, no iníco da sua carreira de crítico militante, fez a seguinte pergunta para o escritor Marco Lodoli, em Istruzioni per L uso del Lupo. Lettera sulla critica (1994): prezado Marco, é possível resenhar-se um pôr-do-sol?

18 Ritorno alla critica, op. cit. p.89.

19 Assim como é esboçada por Andrea Cortelessa, in Scritture-reagente. Di alcune autori-critici contemporanei , in La Critica Dopo la Crisi, a c. di M. Ganeri e N. Merola. Atti del Convegno di Arcavacata, 11-13 novembre 2000, Rubbettino, 2002, pp. 41-83.

20 Feltrinelli, Milano, 1995, pp. 7-16. 
21 M. Onofri, S. Perrella, E. Trevi, Costellazioni Italiane 1945-1999. Libri e autori del secondo Novecento, a c. di A. Donati, Firenze, Le Letere, 1999.

22 Op. cit. p. 35.

23 S. Perrella, Il critico come uomo ovvero L uomo-che-legge, in Giacomo Debenedetti e il Secolo della Critica, Atti del Convegno di Roma, 21-24 febbraio 2001, a c. di A. Berardinelli, G. Ferroni e M. Gaeta, numero monografico di Nuovi Argomenti, V, 15, luglio-settembre 2001, p. 300.

24 Cf. V. Tinacci, O sovra tutte mal creata plebe. Tradimenti congeniti del critico letterario, in Allegoria, $\mathrm{n}$. 42, settembre-dicembre 2002, pp. 153-158.

25 C. Benedetti, Il Tradimento dei Critici, Torino, Bolati Boringhieri, 2002.

26 C. Benedetti, La critica come collaudo , in Rivista dei Libri, n. 10, ottobre 2000, seguido por A. Berardinelli, Teoria e critica con giudizio, ivi, gennaio 2001.

27 G. Debenedetti, Prefazione, in Saggi Critici, Prima Serie, Ed. di Solaria, Firenze, 1929 (Il Saggiatore, Milano, 1971), p.16.

28 Cf. G. Debenedetti, Quaderni di Montaigne, Milano, Grazanti, 1986, pp. 60-65.

29 Entre as metáforas e os apólogos que Debenedetti empregou para dar uma idéia do fazer crítico, as mais célebres são a luta entre Jacó e o anjo, a viagem de Orfeu e o mito de Édipo.

30 Cf. G. Debenedetti, Quaderni di Montaigne, Milano, Garzanti, 1986, pp. 60-65.

31 Com tal afirmação não se pretende padronizar o ensaísmo crítico e filosófico como literatura , compreendida redutivamente como reino do inefável. Significa sim pôr em curto-circuito metáfora e história, e reconhecer, naquele processo de condensação, a matéria prima da experiência . Além do mais, Della Volpe nos ensinou que as figuras retóricas têm uma componente cognitiva, intelectual, que não oculta ou embriaga o pensamento, mas o antecipa, tornando-o mais agudo. Cf. A. Stara, Debenedetti e le metafore , in Paragone, XXXIX, n. 10, agosto 1988, pp. 49-70 e A. Borghesi, Il critico allo specchio: Giacomo Debenedetti e Francesco de Sanctis , in Allegoria, n. 42, settembre-dicembre 2002, pp. 9-37.

32 G. Debenedetti, Il Romanzo del Novecento, Milano, Garzanti, 1971, p. 700.

33 F. Fortini, Più velenoso di quanto pensiate, in Questioni di Frontiera, Torino, Einaudi, 1977, p. 23.

34 Tão densamente profético que acabou por desaguar, no decorrer dos anos Oitenta, na outra expressão, a do japonês que vive em nós .

35 F. Fortini, Comunismo , in Non Solo Oggi, a c. di P. Jachia, Roma, Editori Riuniti, 1991.

36 V. Sereni, Gli Strumenti Umani, Torino, Einaudi, 1965. [N. da T.]

37 In Saggi Italiani, op. cit., pp. 178-188.

38 Trinta e seis curtíssimos retratos - publicados postumamente - de autores e problemas da segunda metade do século XX, Manni Lecce, 1996.

39 Conjunto dos movimentos artístico, literário, estético, desenvolvidos na Itália do século XX. (Zingarelli). Será usado também o termo, na mesma acepção, Novecento. [N. da T.]

40 Como demonstra exemplarmente um romance político, que já do título retoma a idéia do túnel, no qual o atentado terrorista e o cancelamento do herói-que-pensa coincidem: Um barulho. O túnel se ilumina de dia...a montanha treme...um calor assustador se desprende, o vagão atingido é um forno...Tochas humanas se jogam pelas janelas...os mortos são doze, cento e cinqüenta os feridos...Enzo está ao meu lado e dorme. É estranho, está muito quieto...Um infarto. E. Capodaglio, Galleria del Vento, Istmi,Urbania, 2001, p. 208. 